\title{
THE HANSON BROTHERS EFFECT: IS ROUGH PLAY A WINNING STRATEGY IN THE NHL?
}

\author{
Kenneth M. York \\ Oakland University • Rochester, MI \\ Cynthia E. Miree \\ Oakland University • Rochester, MI
}

\section{ABSTRACT}

The effectiveness of "rough play" as an on-ice operational strategy in the National Hockey League (NHL) was examined for the effect on season outcomes (e.g., Stanley Cup playoffs, winning the Stanley Cup), and on-ice performance (e.g., Points, Wins). Four measures of rough play were analyzed (Penalties in Minutes (PIM), number of Major Penalties, number of Minor Penalties, PIM Differential). There were no significant differences between eventual Stanley Cup winners or playoff teams and other teams in the regular season, but Stanley Cup Finalists had significantly fewer PIM. Rough play was not found to be an effective strategy for NHL teams.

Keywords: Strategic management, National Hockey League, firm performance, violence

\section{INTRODUCTION}

Strategic management, as a field, is concerned with understanding and enhancing firm performance. To this end, the vast majority of its sub-disciplines are focused on understanding the contribution of various resources (Barney, 2001), processes (Peng, Quan, Zhang, \& Dubinsky, 2016), activities (Mithas, Ramasubbu, \& Sambamurthy, 2011) or contextual elements (e.g., the macro or industry environment (Tho, 2018; Mukerjee, 2016; Pelham, 1999)) on performance. Given the importance of performance as a key dependent variable, identifying or developing appropriate measures continues to be an important organizational pursuit. Measuring performance in "for profit" organizations typically involves assessing financial and/or market results (Parnell, O’Regan \& Ghobadian, 2006; Aupperle \& Sarhan, 1995; Chakravarthy, 1986; Venkatraman \& Ramanujam, 1986) such as revenue, market share or return on investment. Within the context of sports leagues, indicators of successful performance may be more than winning the championship, it may also include fan attendance, merchandise and ticket sales, competitive balance, advertising or cable contracts (e.g., Laurell \& Soderman, 2018). 
Like many sports leagues, performance within the National Hockey League (NHL) is best understood using a diverse set of player-focused, team-based, and overall league measures. Examples of player-focused measures include statistics such as games played, assists, goals, shots on goal, penalties, etc. Team-based measures include metrics such as fan attendance, ticket sales, wins or losses, team support, and fan satisfaction (e.g., Kennett, Sneath, \& Henson, 2001). At the same time, it should be noted that these intuitive indicators of successful performance such as fan attendance are often influenced by other factors such as violence, typically measured as fights (e.g., Paul, Weinbach, \& Robbins, 2013).

The relationship between game violence and fan attendance has been established in the literature (Rockerbie, 2016). Indeed, the presence and role of different types of specialty players known as enforcers (Burdekin \& Morton, 2015) $\boldsymbol{A N D}$ the value placed on these players (i.e., those who exhibit skills in executing aggressive behaviors) signals a type of acceptance of said roles as an often-necessary aspect of the games based on the positive relationship between violence and revenue (as measured by fan attendance). What remains under-explored however is the relationship between violence and other important measures of performance, such as points or wins.

Again, given that the literature has already demonstrated a positive relationship between fan attendance (as a measure of successful performance) and violence, one might likewise predict a positive relationship between violence and other measures of performance given the persistence of said phenomenon within the NHL. In other words, is the use of violence an effective on-ice operational strategy (i.e., does violence produces wins and championships?), as well as an effective marketing strategy (i.e., is fan attendance related to violence?).

The purpose of the current paper is to explore this relationship within a performance measurement framework known as the Balanced Scorecard (Kaplan and Norton, 2005; 1992). This paper will compare in two related relationships:

1. The impact of violence on participation in the playoffs or winning the championship,

2. The impact of violence on on-ice performance as measured by points or wins. The remaining sections of the paper are arranged as follows. We will briefly explore the purpose of the Balanced Scorecard as a performance measurement system. We will then empirically explore the relationship between violence and performance measures. 


\section{USING THE BALANCED SCORECARD TO UNDERSTAND PERFORMANCE IN THE NHL}

The Balanced Scorecard (Kaplan \& Norton, 2005; 1992) is an analytical framework designed to identify an appropriate set of critical success factors that when implemented lead to successful performance across a range of "balanced" performance measures. The Balanced Scorecard itself is divided into four categories of measures: Financial, Customer, Internal Business Process, and Learning and Growth.

In keeping with Kaplan and Norton (2005), a well-designed Balanced Scorecard would allow management to look at performance from four important perspectives while simultaneously answering the following questions within the NHL:

1. How do customers (e.g., fans) see us? [Customer Perspective]

2. What must we excel at to be successful (e.g., points or wins)? [Internal Business Perspective]

3. Can we continue to improve and create value? [Innovation and Learning Perspective]

4. How do we look to shareholders (e.g., owners and the league as a whole) [Financial Perspective].

From a financial perspective, based on revenues the NHL is one of the four major professional sports played in the U.S., the others being Football (NFL), Baseball (MLB), and Basketball (NBA). To maintain positive revenue streams, different teams choose different styles of play. Further, some styles of play may be more successful than others in drawing fans or winning games or winning the championship. For example, from an "on-ice operational" perspective, some NHL teams may focus on defense, some on offense, some on a balance between offense and defense.

One notable example of this type of choice occurs in the movie "Slap Shot," directed by George Roy Hill. In the movie, a small town's minor league hockey team acquires the Hanson Brothers, who play in an especially rough style, which both brings in big crowds of fans and leads to the team winning the championship (IMDB, 2019). While Hollywood's depiction of the dual and positive impact of rough play on performance may simply represent engaging storytelling, the effectiveness of this type of technical/operational strategy certainly merits further investigation. Fortunately, the NHL keeps multiple statistics on games thereby enabling an empirical test using multiple measures of rough play and multiple measures of outcomes and on-ice performance.

If, indeed, teams employ "rough play" because this type of play is seen as an important aspect of the value-creating process (from both a fan and management 
perspective), the question of the use of enforcers or "rough play" as an effective onice operational strategy still remains. In other words, does a team that has a rough style of play have more on-ice success because of this strategic choice?

To explore this question, we have developed four hypotheses, using multiple measures of performance and both regular season and playoff data. If rough play gives a team a strategic advantage ${ }^{1}$ (on the ice) we predict the following relationships for the NHL regular season:

Hypothesis 1a: Stanley Cup Winners (the championship trophy in the NHL) will have more rough play than the other teams, in the NHL regular season.

Hypothesis 1b: Stanley Cup Finals teams will have more rough play than the other non-Finals teams, in the NHL regular season.

Hypothesis 1c: Stanley Cup Playoff teams will have more rough play than the other non-Playoff teams, in the NHL regular season.

Hypothesis 2a: Rough play will predict whether teams made the Stanley Cup Playoffs or played in the championship series or won the championship, in the NHL regular season.

Hypothesis 2b: Rough play will predict on-ice performance, in the NHL regular season.

If rough play gives teams a strategic advantage (on the ice), we predict the following relationships for the Stanley Cup Playoffs:

Hypothesis 3a: Stanley Cup Winners will have more rough play than the other teams, in the Stanley Cup Playoffs.

Hypothesis 3b: Stanley Cup Finals teams will have more rough play than the other teams, in the Stanley Cup Playoffs.

Hypothesis4a: Rough play will predict whether teams played in the championship series or won the championship, in the Stanley Cup Playoffs.

Hypothesis 4b: Rough play will predict on-ice performance, in the Stanley Cup Playoffs.

\section{METHOD}

The data were obtained from the NHL web page (www.nhl.com), the Hockey Reference web page (https://www.hockey-reference.com/), and the ESPN NHL Team Major Penalties Statistics web page (http://www.espn.com/nhl/statistics/team/_stat/ major-penalties/sort/avgPIM), for the eleven seasons 2008-2009 to 2018-2019. The Hockey Reference web page includes data on Games played, Points, Wins, Losses,

${ }^{1}$ http://www.baldrige21.com/Baldrige_Glossary.html 
and Winners of the Stanley Cup, for the NHL teams, for each regular season and the playoffs. The ESPN Major Penalties web page includes data on Penalties in Minutes (PIM), Major Penalties, Minor Penalties, and Power Play Goals, for each NHL team, for each regular season and the playoffs. In the 2017-2018 season the NHL expanded from 30 to 31 teams. There were 11 seasons of data for 30 teams, and 2 seasons of data for 1 team, making a total of 332 observations.

\section{Direct and Indirect Measures}

We tested whether rough play as measured by penalties, provides a team with a strategic advantage over other teams in terms of season outcomes and on-ice performance. The most important and direct measure of team success is winning the Stanley Cup, the championship for the NHL. We also tested two other direct measures, whether a team played in the Stanley Cup finals, and whether a team was in the Stanley Cup playoffs; these are both indicators of success, but less so than winning the championship. We also tested multiple indirect measures of on-ice performance such as Points, (for the regular season), Wins, and Goals. These are indirect measures of success because a team may score more goals than other teams but not win many games if they allow even more goals, and a team can win more games than any other teams (President's Trophy is awarded to the team with the best overall regular season record) and even play in the Stanley Cup Playoffs, but not win the championship. Across the eleven NHL seasons examined here, the correlation between Wins and Goals was .81, and between Wins and Goals Against was .05.

\section{Rough Play in the NHL}

Teams make a strategic decision about their style of play. Teams can try to avoid being penalized and playing "short-handed" or risk a rougher style of play and having more "power plays" against them. Rough play may give an advantage that is not balanced by the penalties for rough play, and not every violation of the rules results in a penalty being assessed. Another effect is that rough play may have an adverse effect on the play of the opposing team, i.e., the opposing team plays more tentatively, and wins fewer "puck battles," so that rough play may result in more goals scored or fewer goals against them despite having more penalties. Across the eleven NHL seasons examined here, the correlation between Wins and Power Play Goals Against was .04, and between Wins and Power Play Goals .54, which indicates that the greater the number of Power Play Goals scored, the more Wins.

For less serious infractions of the rules such as offside or icing there is not a 
penalty; there is a stoppage in play and a re-start with a face off. For more serious infractions of the rules such as tripping or fighting the penalized team must play with fewer skaters for 2 minutes (for a Minor Penalty such as tripping) or 5 minutes (for a Major Penalty such as fighting), or play the remainder of the game without that player (e.g., game misconduct). The NHL records penalties in two ways: 1) The number of penalties in a game (i.e., the number of each Major Penalties and the number of each Minor Penalty), and 2) Penalties in Minutes (i.e., 3 Minor Penalties at 2 minutes each, plus 1 Major Penalty at 5 minutes, equals 11 PIM). Penalties can be coincidental; both teams are penalized at the same time (4-on-4, "even strength"), and the number of penalties and the PIM are counted. If a penalty is given to only one team, the penalized team plays "short-handed" (e.g., 5-on-4), and it is called a Power Play Opportunity for the team that is not penalized. If a team plays "short-handed," they are more likely to have a goal scored against them than they are to score a goal. Penalties and Power Play Goals are a significant part of the game. In the eleven seasons analyzed here, there were an average of 48.7 Power Play Goals per team each season, and $21.9 \%(16,158$ of 73,741$)$ of the goals scored were Power Play goals, scored while the other team was playing "short-handed" because of a penalty.

\section{Operational Definitions of Variables}

We measured rough play by using NHL penalty data. PIM (Penalties in Minutes) refers to the penalty minutes assessed. PIM is the sum of the minutes assessed for both Major Penalties and Minor Penalties. The number of Major Penalties and Minor Penalties can also be used as measures of "rough play." PIM is the minutes assessed, not the minutes actually served; if a team is playing "shorthanded" because of a Minor Penalty and the opposing team scores, the penalized team returns to "full strength" and the penalized player does not stay in the penalty box for the full time assessed. For a Major Penalty, a player remains in the penalty box for the entire 5 minutes, no matter how many goals the opposing team scores. Also, a team could have multiple, concurrent penalties, which means the team plays "short-handed" by two players. If a player is given a Major Misconduct penalty, the penalized team plays at "full strength" but the penalized player stays in the penalty box for the full time of the penalty (i.e., PIM but not "short-handed"). Or both teams could be given a penalty at the same time and neither team plays "short-handed." So, PIM is not equivalent to "short-handed" time.

We used three outcome measures: 1) whether the team won the Stanley Cup (the championship for the NHL), 2) whether the team played in the final series of 
the Stanley Cup Playoffs, 2 teams each season, and 3) whether the team played in the Stanley Cup playoffs, 16 teams each season. There were also seven on-ice performance measures: 1) Points ( 2 points for a Win, 1 point for a loss in overtime; points are not used in the Stanley Cup playoffs, so this was not used for the analyses using the Stanley Cup Playoff data), 2) Wins, 3) Goal Differential (Goals For minus Goals Against), 4) Goals, 5) Goals Against, 6) Power Play Goals, and 7) Power Play Goals Against.

We also calculated another measure of rough play: PIM Differential (e.g., the PIM for each team minus the PIM for all their opponents in a season). A team that had more PIM than their opponents would have a positive PIM Differential. For these analyses, we calculated each these measures per game to have a common set of measures for the regular season of 82 games and the variable number of games each team plays in the Stanley Cup Playoffs, which are four rounds of best-of-seven series (therefore the number of playoff games played by a team in the Stanley Cup Playoffs varies from as few as 4 to as many as 28 ).

\section{Analyses}

The strategic question for NHL teams is whether rough play is, despite the penalties, associated with more Wins and Points in a season, and the team is more likely to be in the Stanley Cup playoffs, in the finals, and win the championship. To answer the questions, we tested four hypotheses using two different datasets. For the first two hypotheses we used NHL regular season data, and for the second two hypotheses we used Stanley Cup Playoff data. We tested the hypotheses using two different types of measures, direct and indirect. The direct measures were seasonal outcome measures: being in the playoffs, being in the final series of the playoffs, and winning the championship. The indirect measures were on-ice performance measures such as points, wins, and goals.

\section{RESULTS}

\section{NHL Regular Season}

To test Hypothesis 1a, four ANOVAs were calculated using whether or not a team won the Stanley Cup as the classification variable, and four different measures of rough play per game: 1) Penalties in Minutes (PIM), 2) Major Penalties, 3) Minor Penalties, and 4) PIM Differential. Across the eleven NHL seasons analyzed here, PIM was highly correlated with both Major Penalties (.90) and Minor Penalties 
(.88), because the greater the number of Major Penalties and Minor Penalties, the greater the PIM. However, PIM Differential was not highly correlated with PIM (.16), Major Penalties (.09), nor Minor Penalties (.17).

There was no statistically significant difference between Stanley Cup winners and Non-winners in Penalties in Minutes, Major Penalties, Minor Penalties, nor PIM Differential. Although not statistically significant, Stanley Cup Winners had fewer PIM (Stanley Cup Winners $=9.96$ and Non-Winners $=10.76$ ), fewer Major Penalties (Stanley Cup Winners $=0.32$ and Non-Winners $=0.41$ ), fewer Minor Penalties (Stanley Cup Winners $=3.59$ and Non-Winners $=3.68$ ), and smaller PIM Differential (Stanley Cup Winners $=-0.29$ and Non-Winners $=0.01$ ). The results of the analyses are shown in Table 1.

Table 1

\section{Descriptive Statistics of the Sample}

\begin{tabular}{|c|c|c|c|c|c|}
\hline \multirow[b]{2}{*}{ Team } & \multirow[b]{2}{*}{ Seasons } & \multicolumn{4}{|c|}{ Measures of Rough Play - Mean (Standard Deviation) } \\
\hline & & PIM/Game & $\begin{array}{c}\text { Major } \\
\text { Penalties/Game }\end{array}$ & $\begin{array}{c}\text { Minor } \\
\text { Penalties/ } \\
\text { Game }\end{array}$ & $\begin{array}{c}\text { PIM } \\
\text { Differential/ } \\
\text { Game }\end{array}$ \\
\hline Anaheim & 11 & $12.3(2.6)$ & $0.6(0.3)$ & $4.0(0.6)$ & $1.0(1.0)$ \\
\hline Arizona & 11 & $10.1(1.8)$ & $0.3(0.2)$ & $3.7(0.4)$ & $0.7(1.0)$ \\
\hline Boston & 11 & $11.3(1.5)$ & $0.5(0.2)$ & $3.6(0.3)$ & $0.1(0.7)$ \\
\hline Buffalo & 11 & $10.5(2.0)$ & $0.4(0.1)$ & $3.6(0.6)$ & $-0.05(0.8)$ \\
\hline Calgary & 11 & $10.9(2.3)$ & $0.5(0.2)$ & $3.6(0.6)$ & $-0.8(1.2)$ \\
\hline Carolina & 11 & $8.5(2.1)$ & $0.2(0.1)$ & $3.3(0.6)$ & $-0.9(0.5)$ \\
\hline Chicago & 11 & $9.0(2.2)$ & $0.3(0.2)$ & $3.2(0.5)$ & $-0.2(1.8)$ \\
\hline Colorado & 11 & $10.9(1.6)$ & $0.4(0.2)$ & $3.7(0.4)$ & $0.0(0.6)$ \\
\hline Columbus & 11 & $11.3(2.8)$ & $0.5(0.2)$ & $3.7(0.7)$ & $-0.0(0.9)$ \\
\hline Dallas & 11 & $11.0(2.0)$ & $0.4(0.2)$ & $3.8(0.5)$ & $-0.6(0.9)$ \\
\hline Detroit & 11 & $8.9(0.6)$ & $0.2(0.1)$ & $3.6(0.4)$ & $0.1(0.6)$ \\
\hline Edmonton & 11 & $11.3(2.6)$ & $0.5(0.2)$ & $3.7(0.6)$ & $-0.1(0.9)$ \\
\hline Florida & 11 & $10.1(1.1)$ & $0.4(0.1)$ & $3.5(0.3)$ & $-0.05(0.6)$ \\
\hline Los Angeles & 11 & $10.6(1.8)$ & $0.4(0.1)$ & $3.7(0.6)$ & $0.0(0.6)$ \\
\hline Minnesota & 11 & $9.7(1.9)$ & $0.3(0.1)$ & $3.5(0.5)$ & $-0.5(0.8)$ \\
\hline Montreal & 11 & $11.2(2.2)$ & $0.4(0.1)$ & $4.0(0.6)$ & $0.1(0.9)$ \\
\hline Nashville & 11 & $9.6(1.3)$ & $0.3(0.1)$ & $3.4(0.4)$ & $-0.2(0.8)$ \\
\hline New Jersey & 11 & $10.0(1.4)$ & $0.4(0.2)$ & $3.5(0.4)$ & $0.6(0.9)$ \\
\hline NY Islanders & 11 & $10.7(3.4)$ & $0.4(0.2)$ & $3.5(0.6)$ & $-0.5(0.8)$ \\
\hline NY Rangers & 11 & $10.6(2.6)$ & $0.4(0.2)$ & $3.6(0.5)$ & $0.6(1.2)$ \\
\hline Ottawa & 11 & $11.8(2.3)$ & $0.5(0.1)$ & $3.9(0.6)$ & $0.3(1.0)$ \\
\hline Philadelphia & 11 & $13.0(3.3)$ & $0.5(0.3)$ & $4.1(0.8)$ & $-0.0(0.7)$ \\
\hline Pittsburgh & 11 & $11.5(2.9)$ & $0.4(0.2)$ & $4.0(0.6)$ & $-0.1(0.8)$ \\
\hline San Jose & 11 & $10.0(2.0)$ & $0.4(0.2)$ & $3.4(0.6)$ & $-0.8(1.0)$ \\
\hline St. Louis & 11 & $11.9(3.0)$ & $0.5(0.3)$ & $3.9(0.6)$ & $0.1(0.6)$ \\
\hline Tampa Bay & 11 & $11.4(2.6)$ & $0.4(0.2)$ & $4.0(0.6)$ & $-0.1(1.0)$ \\
\hline Toronto & 11 & $10.9(3.0)$ & $0.5(0.3)$ & $36(0.5)$ & $-0.2(0.7)$ \\
\hline Vancouver & 11 & $11.7(2.8)$ & $0.4(0.2)$ & $3.9(0.7)$ & $0.4(0.6)$ \\
\hline Vegas & 2 & $7.0(0.2)$ & $0.1(0.0)$ & $3.0(0.0)$ & $0.3(0.5)$ \\
\hline Washington & 11 & $10.4(1.2)$ & $0.3(0.1)$ & $3.8(0.4)$ & $0.3(0.6)$ \\
\hline Winnipeg/Atlanta & 11 & $11.4(1.9)$ & $0.4(0.2)$ & $4.0(0.6)$ & $0.6(0.6)$ \\
\hline Mean & & $10.6(2.1)$ & $0.4(0.2)$ & $3.7(0.5)$ & $0.0(0.8)$ \\
\hline
\end{tabular}


To test Hypothesis 1b, four ANOVAs were calculated using whether or not a team was in the Stanley Cup finals in a season as the classification variable, and the same four measures of rough play used above. There was no significant difference between Stanley Cup finalists and Non-Finalists in Penalties in Minutes, Major Penalties, Minor Penalties, nor PIM Differential. Although not statistically significant, Stanley Cup Finalists had fewer PIM (Stanley Cup Finalists $=10.26$ and Non-Finalists $=10.77$ ), fewer Major penalties (Stanley Cup Finalists $=0.35$ and Non-Finalists $=0.41$ ), fewer Minor penalties (Stanley Cup Finalists $=3.65$ and NonFinalists $=3.68$ ), and smaller PIM Differential (Stanley Cup Winners $=-0.18$ and Non-Winners $=0.01$ ). The results of the analyses are shown in Table 2 .

Table 2

ANOVA of Stanley Cup Winners and Non-Winners, with Four Measures of Rough Play, Regular Season

\begin{tabular}{|c|c|c|c|c|c|}
\hline Comparison & Measure of Rough Play & $\mathrm{F}$ & $p$ & \multicolumn{2}{|c|}{ Means } \\
\hline \multirow{4}{*}{$\begin{array}{l}\text { Stanley Cup } \\
\text { Winners vs. others }\end{array}$} & Penalties in Minutes/Game & 1.19 & .275 & 9.96 & 10.76 \\
\hline & Major Penalties/Game & 1.97 & .161 & 0.32 & 0.41 \\
\hline & Minor Penalties/Game & 0.27 & .607 & 3.59 & 3.68 \\
\hline & PIM Differential/Game & 1.07 & .302 & -0.29 & 0.01 \\
\hline \multirow{4}{*}{$\begin{array}{l}\text { Stanley Cup } \\
\text { Finalists vs. others }\end{array}$} & Penalties in Minutes/Game & 0.94 & .334 & 10.26 & $\mathbf{1 0 . 7 7}$ \\
\hline & Major Penalties/Game & 1.53 & .217 & 0.35 & 0.41 \\
\hline & Minor Penalties/Game & 0.08 & .776 & 3.65 & 3.68 \\
\hline & PIM Differential/Game & 0.82 & .367 & -0.18 & 0.01 \\
\hline \multirow{4}{*}{$\begin{array}{l}\text { Stanley Cup } \\
\text { Playoffs vs. others }\end{array}$} & Penalties in Minutes/Game & 0.01 & .929 & 10.72 & 10.75 \\
\hline & Major Penalties/Game & 1.53 & .217 & 0.39 & 0.42 \\
\hline & Minor Penalties/Game & 0.92 & .338 & 3.71 & 3.65 \\
\hline & PIM Differential/Game & 3.47 & .063 & -0.09 & 0.10 \\
\hline \multicolumn{6}{|c|}{$\begin{array}{l}\text { Note. PIM Differential/Game }=\text { PIM/Game }- \text { Opponents PIM/Game. Bolded values indicate } \\
\text { a greater number of Penalties in Minutes, Number of Major penalties/Game, Number of Minor } \\
\text { penalties, PIM Differential. } *=p<.05 \text {. Analysis includes } 11 \text { seasons, 2008-2009 to } 2018 \text { - } \\
\text { 2019. In the seasons } 2008-2017 \text { there were } 30 \text { NHL teams, and starting in } 2017-2018 \text { there } \\
\text { were } 31 \text {. }\end{array}$} \\
\hline
\end{tabular}

To test Hypothesis 1c, four ANOVAs were calculated using whether or not a team was in the Stanley Cup Playoffs in a season as the classification variable, and the same four measures of rough play used above. There was no significant difference between Stanley Cup Playoff teams and Non-Stanley Cup Playoff teams in Penalties in Minutes, Major Penalties, Minor Penalties, nor PIM Differential. Although not statistically significant, Stanley Cup Playoff teams had fewer PIM (Stanley Cup Playoff teams $=10.72$ and Non-Stanley Cup Playoff teams $=10.75$ ), fewer Major penalties (Stanley Cup Playoff teams $=0.39$ and Non-Playoff teams $=0.42$ ), but more Minor penalties (Stanley Cup Playoff teams $=3.71$ and Non-Stanley Cup Playoff teams $=$ 
3.65), and smaller PIM Differential (Stanley Cup Playoff teams = -.09 and Non-Stanley Cup Playoff teams $=0.10$. The results of the analyses are shown in Table 1 .

Penalties in Minutes was not stable across the seasons analyzed here. PIM declined in the NHL from the 2008-2009 to 2018-2019 season (13.9 to 8.3 per game for all NHL teams, 13.6 to 7.6 per game for the Stanley Cup winners), and the eventual Stanley Cup winner had a lower PIM per Game than the non-playoff teams in every season except 2017-2018. Repeated Measures ANOVA on PIM per Game over the 11 seasons for all NHL teams showed there was a statistically significant within effect $(\mathrm{F}(10,290)=47.70, p=.000)$, and the Polynomial Test of Order was statistically significant for Linear, $\mathrm{F}(1,29)=180.10, p=.001$. Statistically significant within effects and Linear polynomial test were also found for Major Penalties and Minor Penalties, but not for PIM Differential. The values for PIM per Game by season for all NHL Teams are shown in Figure 1. The values of PIM per Game for Stanley Cup Winners, Stanley Cup Finalists, and non-playoff teams for each Regular Season from 2008-2009 to 2018-2019 are shown in Figure 2.

Figure 1

PIM per Game, all NHL Teams, Regular Season

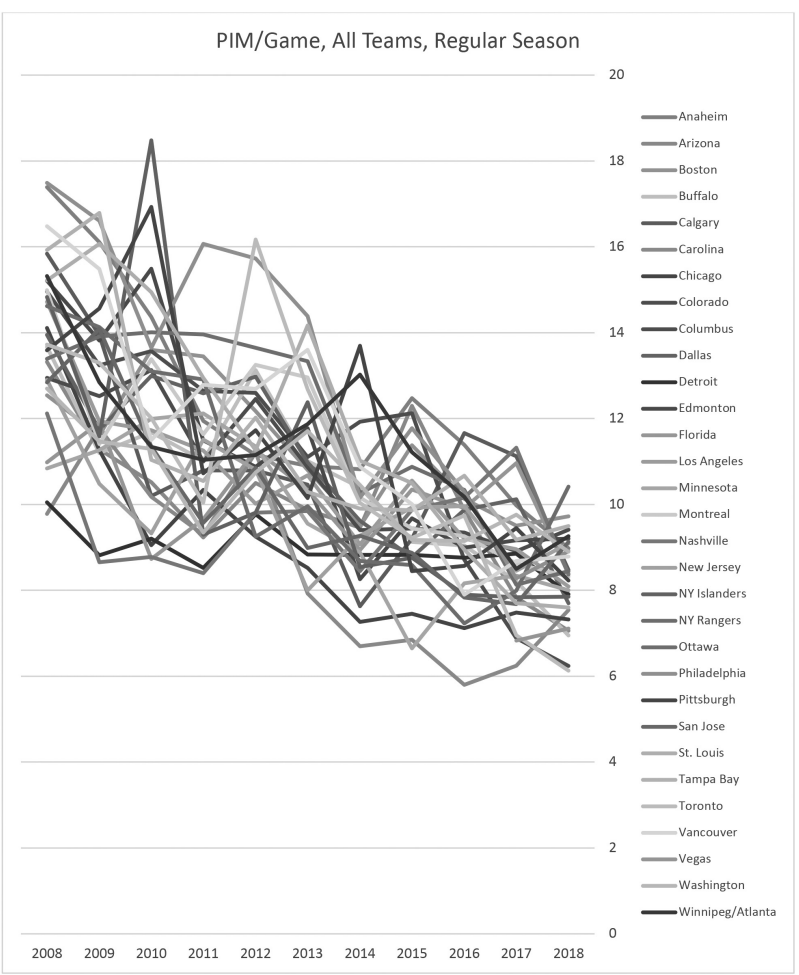




\section{Figure 2}

\section{PIM per Game, Stanley Cup Winners, Playoff Teams, and Non-Playoff Teams, By Season, Regular Season}



To test Hypothesis $2 \mathrm{a}$ and $2 \mathrm{~b}$, ten sets of regression analyses were done. The regressions used the Penalties in Minutes and PIM Differential as the set of independent variables to predict Winning the Stanley Cup, Stanley Cup Finalist, and Stanley Cup Playoffs (these were logistic regressions because the dependent variable was binary), Points, Wins, Goal Differential, Goals, Goals Against, Power Play Goals, or Power Play Goals Against (these were linear regressions because the dependent variable was continuous). Although Number of Major Penalties and Number of Minor Penalties are different measures of rough play than PIM and PIM Differential, the intercorrelations of the four measures (ranging from ranging from .09 to .90) were high enough to cause multicollinearity, so only PIM and PIM Differential (which were correlated .16, and Tolerance was acceptably low at .976) were used in the regression analyses. Being in the Stanley Cup Playoffs or the Finals or winning the championship was not predicted from rough play. The set of two measures of rough play predicted Goal Differential, Goals Against, Power Play Goals, and Power Play Goals Against, with variance accounted for ranging from 2\% to $14 \%$. The results of these analyses are shown in Table 3 . 
Table 3

\section{Logistic and Linear Regression Analyses Predicting Stanley Cup Playoff}

Outcomes and On-Ice Performance from Penalties in Minutes and PIM

\section{Differential, Regular Season}

\begin{tabular}{|c|c|c|c|c|c|c|c|c|c|c|}
\hline \multicolumn{9}{|c|}{ Direct Measures of Season Outcomes - Logistic Regression } & & \\
\hline & \multicolumn{2}{|c|}{ Model Fit } & & & \multicolumn{6}{|c|}{$\begin{array}{c}\text { Measure of Rough Play- Parameter Estimate } \\
\text { (Standard Error) }\end{array}$} \\
\hline & $\begin{array}{r}\text { Chi } \\
\text { Square }\end{array}$ & $p$ & & $\begin{array}{l}\text { McFadd } \\
\text { en's Rho } \\
\text { Squared }\end{array}$ & $\begin{array}{l}\text { PIM } \\
\text { per } \\
\text { Game }\end{array}$ & $p$ & $\begin{array}{l}\text { PIM } \\
\text { Differen } \\
\text { tial per } \\
\text { Game }\end{array}$ & $p$ & Constant & $p$ \\
\hline $\begin{array}{l}\text { Win } \\
\text { Stanley } \\
\text { Cup }\end{array}$ & 2.01 & .367 & & .02 & $\begin{array}{l}.133 \\
(.143)\end{array}$ & .352 & $\begin{array}{c}.283 \\
(.332)\end{array}$ & .394 & $\begin{array}{r}2.04 \\
(1.48)\end{array}$ & .170 \\
\hline $\begin{array}{l}\text { Stanley } \\
\text { Cup } \\
\text { Finalist }\end{array}$ & 1.54 & .463 & & .01 & $\begin{array}{l}.080 \\
(.099)\end{array}$ & .831 & $\begin{array}{l}.180 \\
(.239)\end{array}$ & .752 & $\begin{array}{r}1.80 \\
(1.05)\end{array}$ & .086 \\
\hline $\begin{array}{l}\text { Stanley } \\
\text { Cup } \\
\text { Playoffs }\end{array}$ & 3.52 & .172 & & .01 & $\begin{array}{l}-.010 \\
(.047)\end{array}$ & .838 & $\begin{array}{l}.223 \\
(.120)\end{array}$ & .063 & $\begin{array}{r}-0.02 \\
(0.517)\end{array}$ & .971 \\
\hline \multicolumn{11}{|c|}{ Indirect Measures of On-Ice Performance - Linear Regression } \\
\hline & & & & & \multicolumn{6}{|c|}{$\begin{array}{c}\text { Measure of Rough Play - Standardized Regression } \\
\text { Coefficient (Standard Error) }\end{array}$} \\
\hline & $\mathrm{F}$ & $p$ & RSQ & $\begin{array}{l}\text { Adj- } \\
\text { RSQ }\end{array}$ & $\begin{array}{l}\text { PIM } \\
\text { per } \\
\text { Game }\end{array}$ & $p$ & $\begin{array}{l}\text { PIM } \\
\text { Differen } \\
\text { tial per } \\
\text { Game } \\
\end{array}$ & $p$ & Constant & $p$ \\
\hline $\begin{array}{l}\text { Points per } \\
\text { Game }\end{array}$ & 2.86 & .059 & .02 & .01 & $\begin{array}{r}.051 \\
(.004)\end{array}$ & .359 & $\begin{aligned}-.129 * \\
(.010)\end{aligned}$ & .021 & $\begin{array}{l}.000 * \\
(.044)\end{array}$ & .000 \\
\hline $\begin{array}{l}\text { Wins per } \\
\text { Game }\end{array}$ & 2.39 & .093 & .01 & .01 & $\begin{array}{r}.039 \\
(.002)\end{array}$ & .704 & $\begin{array}{l}-.119 * \\
(.005)\end{array}$ & .032 & $\begin{array}{l}.000 * \\
(.023)\end{array}$ & .000 \\
\hline $\begin{array}{l}\text { Goal } \\
\text { Differenti } \\
\text { al per } \\
\text { Game }\end{array}$ & 4.54* & .011 & .03 & .02 & $\begin{array}{r}.039 \\
(.011)\end{array}$ & .481 & $\begin{array}{l}-.165^{*} \\
(.027)\end{array}$ & .003 & $\begin{array}{r}.000 \\
(.117)\end{array}$ & .490 \\
\hline $\begin{array}{l}\text { Goals per } \\
\text { Game }\end{array}$ & 2.06 & .130 & .01 & .01 & $\begin{array}{r}-.014 \\
(.007) \\
\end{array}$ & .800 & $\begin{aligned}-.108 \\
(.018)\end{aligned}$ & .052 & $\begin{array}{l}.000 * \\
(.078)\end{array}$ & .000 \\
\hline $\begin{array}{l}\text { Goals } \\
\text { Against } \\
\text { per Game }\end{array}$ & $3.62 *$ & .028 & .02 & .02 & $\begin{array}{r}-.072 \\
(.007)\end{array}$ & .196 & $\begin{array}{l}.140 * \\
(.018)\end{array}$ & .012 & $\begin{array}{l}.000 * \\
(.079)\end{array}$ & .000 \\
\hline $\begin{array}{l}\text { Power } \\
\text { Play } \\
\text { Goals }\end{array}$ & 23.98* & .000 & .13 & .12 & $\begin{array}{r}.340 \\
(.003)\end{array}$ & .000 & $\begin{array}{r}-.172 * \\
(.007)\end{array}$ & .001 & $\begin{array}{l}.000 * \\
(.031)\end{array}$ & .000 \\
\hline $\begin{array}{l}\text { Power } \\
\text { Play } \\
\text { Goals } \\
\text { Against }\end{array}$ & 28.52* & .000 & .15 & .14 & $\begin{array}{r}.314 \\
(.003)\end{array}$ & .000 & $\begin{array}{l}.178^{*} \\
(.007)\end{array}$ & .001 & $\begin{array}{l}.000 * \\
(.030)\end{array}$ & .000 \\
\hline
\end{tabular}


In summary, for multiple tests of the two hypotheses there was no support for the hypotheses that teams that had more rough style of play were more successful in terms of making the Stanley Cup Playoffs, making it to the finals, or winning the championship, across 11 NHL regular seasons. There was weak support for rough play predicting the indirect measures of on-ice performance, such as goals and power play goals. These results indicate that rough play does not give teams a strategic advantage in getting to the Stanley Cup Playoffs, getting to the Stanley Cup Playoffs, or in winning the Stanley Cup, but there was a relationship between rough play and indirect measures of on-ice performance. However, whatever advantage the teams may have gained from rough play in the regular season, did not translate into winning the championship.

\section{Stanley Cup Playoffs}

Hypotheses $3 \mathrm{a}$ and $3 \mathrm{~b}$ were tested and the results were similar to the regular season data. There was one significant difference between Stanley Cup Finalists and other teams in the playoffs: Stanley Cup finalists had significantly fewer PIM per Game than the other teams in the playoffs (10.41 versus 12.58). There were no other statistically significant differences between Stanley Cup winners or Finalists and other playoff teams in Penalties in Minutes, Major Penalties, Minor Penalties, nor PIM Differential. The results of these analyses are shown in Table 4.

\section{Table 4}

NOVA of Stanley Cup Winners and Non-Winners, with Four Measures of Rough Play, Stanley Cup Playoffs

\begin{tabular}{|c|c|c|c|c|c|}
\hline Comparison & Measure of Rough Play & $\mathrm{F}$ & $p$ & \multicolumn{2}{|c|}{ Means } \\
\hline $\begin{array}{l}\text { Stanley Cup } \\
\text { Winners vs. others }\end{array}$ & & & & Winner & Others \\
\hline & Penalties in Minutes/Game & 2.09 & .150 & 10.28 & 12.44 \\
\hline & Major Penalties/Game & 0.67 & .414 & 0.11 & $\mathbf{0 . 1 7}$ \\
\hline & Minor Penalties/Game & 1.11 & .293 & 3.88 & 4.20 \\
\hline & PIM Differential/Game & 2.12 & .147 & -0.85 & 0.52 \\
\hline $\begin{array}{l}\text { Stanley Cup } \\
\text { Finalists vs. others }\end{array}$ & & & & Finalist & Others \\
\hline & Penalties in Minutes/Game & $3.97 *$ & .048 & 10.41 & 12.58 \\
\hline & Major Penalties/Game & 1.07 & .303 & 0.12 & $\mathbf{0 . 1 7}$ \\
\hline & Minor Penalties/Game & 2.37 & .126 & 3.88 & 4.22 \\
\hline & PIM Differential/Game & 3.62 & .059 & -0.71 & 0.60 \\
\hline
\end{tabular}


As in the regular season, PIM per Game also declined in the Stanley Cup Playoffs from the 2008-2009 to 2018-2019 season (15.4 to 9.8 per game for all playoff teams, 11.8 to 7.2 per game for the Stanley Cup winners), and the eventual Stanley Cup winner had a lower PIM than the other the playoff teams in every season except 2010-2011 and 2016-2017. Because only 16 teams are in the Stanley Cup Playoffs and different teams each season, a Repeated Measures ANOVA on PIM cannot be done here as was done for the regular season data on all the teams. The values for PIM per Game by season for Stanley Cup Winners, Stanley Finalists, and all playoff teams for each season 2008-2009 to 2018-2019 are shown in Figure 3.

Figure 3

\section{PIM per Game, Stanley Cup Winners, Finalist, and Other Playoff Teams, By Season, Stanley Cup Playoffs}

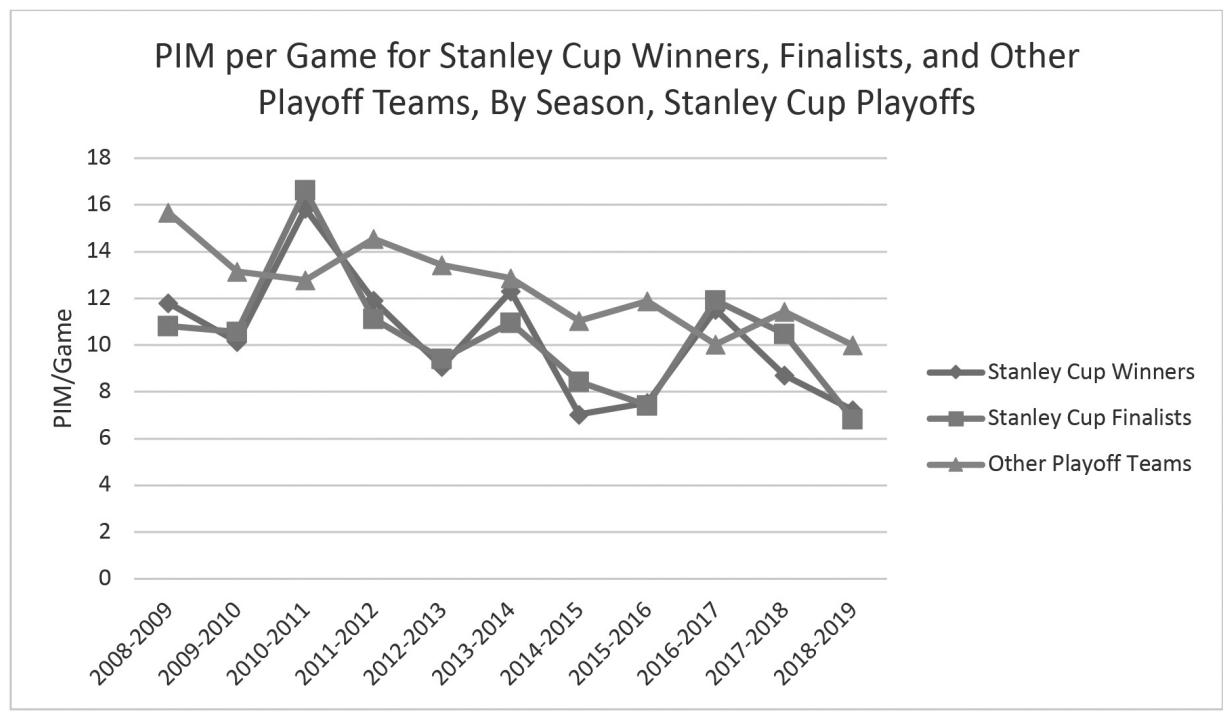

To test Hypothesis $4 \mathrm{a}$ and $4 \mathrm{~b}$, ten sets of regression analyses were done, the same analyses as was done on NHL regular season data. The regressions used Penalties in Minutes and PIM Differential as the set of independent variables to predict Winning the Stanley Cup, playing in the Stanley Cup Finals (these were logistic regressions because the dependent variable was binary), Points, Wins, Goal Differential, Goals, Goals Against, Power Play Goals, or Power Play Goals Against (these were linear regressions because the dependent variable was continuous). As with the regular season data, the intercorrelations among the four measures of rough play (ranging from .06 to .70 ) were high enough to cause multicollinearity, so only 
PIM and PIM Differential (which were correlated .32, Tolerance was acceptably low at .898) were used in the regression analyses. The two measures of rough play did not predict winning the Stanley Cup or being in finals, but did predict most of the indirect measures of on ice-performance (but not Power Play Goals). The results of these analyses are shown in Table 5.

\section{Table 5}

Logistic and Linear Regression Analyses Predicting Stanley Cup Playoff

Outcomes and On-Ice Performance from Penalties in Minutes and PIM Differential, Stanley Cup Playoffs

\begin{tabular}{|c|c|c|c|c|c|c|c|c|c|c|}
\hline \multicolumn{11}{|c|}{ Direct Measures of Season Outcomes - Logistic Regression } \\
\hline & & & & & \multicolumn{6}{|c|}{$\begin{array}{l}\text { Measure of Rough Play- Parameter Estimate } \\
\text { (Standard Error) }\end{array}$} \\
\hline & $\begin{array}{l}\text { Chi- } \\
\text { Square }\end{array}$ & $p$ & & $\begin{array}{r}\text { McFad } \\
\text { den's } \\
\text { Rho- } \\
\text { Square } \\
\text { d }\end{array}$ & $\begin{array}{l}\text { PIM } \\
\text { per } \\
\text { Game }\end{array}$ & $p$ & $\begin{array}{l}\text { PIM } \\
\text { Different } \\
\text { ial per } \\
\text { Game }\end{array}$ & $p$ & Constant & $p$ \\
\hline $\begin{array}{l}\text { Win } \\
\text { Stanley } \\
\text { Cup }\end{array}$ & 3.81 & .149 & & .05 & $\begin{array}{l}.112 \\
(.094)\end{array}$ & .236 & $\begin{array}{r}.124 \\
(.112)\end{array}$ & .269 & $\begin{array}{r}1.478 \\
(1.046)\end{array}$ & .158 \\
\hline $\begin{array}{l}\text { Stanley } \\
\text { Cup } \\
\text { Finalist }\end{array}$ & $6.73 *$ & .035 & & .05 & $\begin{array}{r}.109 \\
(.068)\end{array}$ & .109 & $\begin{aligned} .116 \\
(.084)\end{aligned}$ & .168 & $\begin{array}{l}0.717 \\
(.767)\end{array}$ & .350 \\
\hline \multicolumn{11}{|c|}{ Indirect Measures of On-Ice Performance - Linear Regression } \\
\hline & & & & & \multicolumn{6}{|c|}{$\begin{array}{l}\text { Measure of Rough Play - Standardized Regression } \\
\text { Weights }\end{array}$} \\
\hline & $\mathrm{F}$ & $p$ & RSQ & $\begin{array}{l}\text { Adj- } \\
\text { RSQ }\end{array}$ & $\begin{array}{l}\text { PIM } \\
\text { per } \\
\text { Game }\end{array}$ & $p$ & $\begin{array}{l}\text { PIM } \\
\text { Different } \\
\text { ial per } \\
\text { Game }\end{array}$ & $p$ & Constant & $p$ \\
\hline $\begin{array}{l}\text { Wins per } \\
\text { Game }\end{array}$ & $12.95 *$ & .000 & .13 & .12 & $\begin{array}{r}-.097 \\
(.003)\end{array}$ & .198 & $\begin{array}{r}-.318 * \\
(.003)\end{array}$ & .000 & $\begin{array}{l}.000 * \\
(.036)\end{array}$ & .000 \\
\hline $\begin{array}{l}\text { Goal } \\
\text { Different } \\
\text { ial per } \\
\text { Game }\end{array}$ & 21.67* & .000 & .20 & .19 & $\begin{array}{l}-.157^{*} \\
(.013)\end{array}$ & .030 & $\begin{array}{l}-.372 \% \\
(.020)\end{array}$ & .000 & $\begin{array}{l}.000 * \\
(.165)\end{array}$ & .694 \\
\hline $\begin{array}{l}\text { Goals per } \\
\text { Game }\end{array}$ & 7.06* & .001 & .08 & .07 & $\begin{array}{r}.096 \\
(.010)\end{array}$ & .214 & $\begin{array}{l}-.290 * \\
(.016)\end{array}$ & .000 & $\begin{array}{l}.000 * \\
(.128)\end{array}$ & .000 \\
\hline $\begin{array}{l}\text { Goals } \\
\text { Against } \\
\text { per } \\
\text { Game }\end{array}$ & 18.36* & .000 & .18 & .17 & $.297 *$ & .000 & $.214 *$ & .004 & $\begin{array}{l}.000 * \\
(.127)\end{array}$ & .000 \\
\hline $\begin{array}{l}\text { Power } \\
\text { Play } \\
\text { Goals }\end{array}$ & 1.67 & .314 & .01 & .00 & $\begin{array}{r}-.084 \\
(.013)\end{array}$ & .292 & $\begin{array}{r}-.056 \\
(.021)\end{array}$ & .481 & $\begin{array}{l}.000 * \\
(.171)\end{array}$ & .000 \\
\hline $\begin{array}{l}\text { Power } \\
\text { Play } \\
\text { Goal } \\
\text { Against }\end{array}$ & 25.65* & .000 & .22 & .23 & $\begin{array}{l}.399 * \\
(.005)\end{array}$ & .000 & $\begin{array}{l}.165^{*} \\
(.008)\end{array}$ & .020 & $\begin{array}{l}.000 * \\
(.065)\end{array}$ & .000 \\
\hline
\end{tabular}


The results of these analyses of Stanley Cup Playoff data showed that rough play did not give Stanley Cup Playoff teams a strategic advantage in making it to the Stanley Cup finals, or in winning the Stanley Cup. There was mixed evidence that rough play gave teams a strategic advantage in indirect measures of on-ice performance, but whatever advantage the teams may have gained in playoff games, it did affect winning the championship.

\section{DISCUSSION AND LIMITATIONS}

We tested whether rough play gives NHL teams a strategic advantage across 11 regular seasons and the Stanley Cup Playoffs (2008-2009 to 2018-2019) using four different measures of rough play: Penalties in Minutes, Number of Major Penalties, Number of Minor Penalties, and PIM Differential. We used multiple direct and indirect measures of on-ice performance: participation in the Stanley Cup Playoffs, participation in the championship series, and winning the Stanley Cup, as well as Points, Wins, Goal Differential, Goals, Goals Against, Power Play Goals, and Power Play Goals Against. While there was some support for a strategic advantage for rough play for indirect measures of on-ice performance, we found no support for the idea that rough play gives team a strategic advantage in getting in the Stanley Cup Playoffs, being one of the two teams in the Stanley Cup Finals, nor winning the Stanley Cup.

Although hockey is best described as a "rough sport," in contrast to the "Hanson Brothers Effect" depicted by Hollywood, our results indicate that there is no significant strategic advantage to rough play. In fact, and by sharp contrast, looking at penalties minutes over the 11 seasons examined here, PIM in both the NHL regular season games and the Stanley Cup Playoff games decreased over time. Rather than some teams choosing a rougher style of play than other teams and being more successful in terms of being in the playoffs, in the finals, or winning the championship, there was a decrease in PIM for NHL teams over the 11 seasons analyzed here, in both the regular season and the Stanley Cup Playoffs. This may indicate that NHL teams are collectively choosing a less rough style of play, perhaps with the goal of reducing the number of Power Play Goals scored against them. A change in referee enforcement policy or rule changes are possible alternative explanations for the downward trend in PIM (i.e., a history effect), but we know of no announced change in enforcement policy or rule changes during the 11 seasons analyzed here. In fact, the downward trend in PIM seen in our data is consistent with a long-term trend in the NHL. In the 1987-1988 season (a decade after the movie "Slapshot" and the oldest data available on Hockey-Reference), the league average 
PIM per Game was 26.4 and $30.0 \%$ of Goals were Power Play Goals Against, compared to the 2018-2019 season of 8.3 PIM per Game and 19.3\% of Goals were Power Play Goals Against. A question for future research is to determine whether the trend of decreasing PIM over the eleven NHL seasons analyzed in this study is of recent origin.

There are several limitations to the current study which merit more discussion. First and foremost, is the way that PIM is counted by the NHL. A team is assessed two minutes (PIM) for a Minor Penalty and 5 minutes for a Major Penalty whether the penalty gives the team a power play (and they are more likely to score than when they are "even-strength") or is a coincidental penalty where the opposing team is also given a penalty and there is no power play. A greater PIM indicates more rough play, but not every PIM is a power play.

This study examined PIM Differential over the games played in the regular season and in the playoffs, future research might examine individual game data, to test whether in games in which one team had significantly more penalties (i.e., more rough play) than their opponent was less likely to win the game. Also, NHL data was analyzed here, future research may be directed at investigating whether these results generalize to minor hockey leagues (e.g., American Hockey League), where a greater share of team revenues come from ticket sales than TV contracts.

Another limitation to this study is that teams vary not only in their playing style, but in the quality of the teams. The Strength of Schedule (a rating of the difficulty or ease of a team's opponents as compared to other teams) and Simple Rating System (a team rating that takes into account average goal differential and strength of schedule) reported by Hockey Refererence are ways to measure the quality of a team. A "better" team may have a high PIM and more wins, because the quality of the team can overcome having more penalties against them for rough play.

A third limitation of the study is that an experiment cannot be done here; researchers can only examine penalties as an indicator of the rough play of different teams and their outcomes such as goals, wins, playoffs, and championships. Teams cannot be randomly assigned to "normal play" and "rough play" conditions and then the two groups compared on their on-ice performance.

\section{CONCLUSION}

Sports teams, including the teams of the NHL, have more than one objective, some may focus more on trying to win the championship (the Stanley Cup for the $\mathrm{NHL}$ ), and some may focus more on money (gate receipts, concessions, merchandise, 
TV contracts, etc.). Indeed, there are some teams which focus on both. In the movie "Slap Shot," rough play supported a compelling Hollywood ending wherein rough play helped the Charlestown Chiefs win the championship. While the current findings do not support a significant role for rough play in winning the Stanley Cup, future research may test whether rough play gives an advantage beyond gate receipts in attracting fans and examine revenues generated by selling more luxury boxes, more concessions, more merchandise, etc.

An alternative explanation for the weak support that rough play gives teams an on-ice advantage over other teams is that there is might not be sufficient variability in the level of rough play across teams. The direct effect of playing "short-handed," plus the indirect effect of rough play when playing "even-strength," may not be great enough to have an effect on wins, even in the Stanley Cup Playoffs. Either way, given how violence within the NHL is increasingly being perceived as negative and inappropriate (WSJ, 2011; Gatehouse, 2011), and ineffective in terms of successful on-ice performance (Leard and Doyle, 2011; Engelhardt, 1995), the current results add to the body of work that questions the true contribution of violence to successful performance within the NHL.

\section{REFERENCES}

Barney, J. B. (2001). Resource-based theories of competitive advantage: A ten-year retrospective on the resource-based view. Journal of Management, 27(6), 643-650.

Burdekin, R. C. K., \& Morton, M. G. (2015). Blood money: Violence for hire in the National Hockey League. International Journal of Sport Finance, 10(4), 328-356.

Engelhardt, G. (1995). Fighting behavior and winning National Hockey League games: A paradox. Perceptual and Motor Skills, 80, 416-418.

ESPN.COM (2020). NHL Team Major Penalties Statistics. http://www.espn.com/ nhl/statistics/team/ /stat/major-penalties/sort/avgPIM

Gatehouse, J. (2011, Mar 28). Hockey violence: 'It's time to draw the line': The NHL may finally be getting the message, but fans don't think it's enough, reports Jonathon Gatehouse. Maclean's, 124, 22. Retrieved from https://search. proquest.com/docview/858329236?

Hockey-Reference.com (2020). Seasons. https://www.hockey-reference.com/.

Kaplan, R. S., \& Norton, D. P. (2005, Jul). The Balanced Scorecard: Measures that drive performance. Harvard Business Review, 83, 172-180.

Kaplan, R. S., \& Norton, D. P. (1992, January). The Balanced Scorecard - measures that drive performance. Harvard Business Review, 70, 71-79. 
Kennett, P. A., Sneath, J. Z., \& Henson, S. (2001). Fan satisfaction and segmentation: A case study of minor league hockey spectators. Journal of Targeting, Measurement and Analysis for Marketing, 10(2), 132-142.

Laurell, C., \& Soderman, S. (2018). Sport in business studies: A state-of-the-art literature review. Sport, Business and Management, 8(5), 529-546.

Leard, B., \& Doyle, J. M. (2011). The effect of home advantage, momentum, and fighting on winning in the National Hockey League. Journal of Sports Economics, 12(5), 538-560.

Mithas, S., Ramasubbu, N., \& Sambamurthy, V. (2011). How information management capability influences firm performance. MIS Quarterly, 35(1), 237-256.

Mukerjee, K. (2016). Factors that contribute towards competitive advantage: A conceptual analysis. IUP Journal of Business Strategy, 13(1), 26-39.

National Hockey League. (2020). Stats. http://www.nhl.com.

Parnell, J. A., O’Regan, N., \& Ghobadian, A. (2006). Measuring performance in competitive strategy research. International Journal of Management \& Decision Making, 7(4), 408-417.

Paul, R. J., Weinbach, A. P., \& Robbins, D. (2013). American Hockey League attendance: A study of fan preferences for fighting, team performance, and promotions. International Journal of Sport Finance, 8(1), 21-38.

Peng, J., Quan, J., Zhang, G., \& Dubinsky, A. J. (2016). Mediation effect of business process and supply chain management capabilities on the impact of IT on firm performance: Evidence from Chinese firms: SSIS. International Journal of Information Management, 36(1), 89-96.

Pelham, A. M. (1999). Influence of environment, strategy, and market orientation on performance in small manufacturing firms. Journal of Business Research, 45(1), 33-46.

Rockerbie, D. W. (2016). Fighting as a profit maximizing strategy in the National Hockey League: More evidence. Applied Economics, 48(4), 292-299.

Slap Shot. (2020). Internet Movie Database. Retrieved April 20, 2020, from https://www.imdb.com/title/tt0076723/.

Tho, N. D. (2018). Firm capabilities and performance: A necessary condition analysis. The Journal of Management Development, 37(4), 322-332

WSJ: Air Canada threatens to end NHL sponsorship over violence. (2011, Mar 10). Dow Jones Institutional News. Retrieved from https://search.proquest.com/ docview/2156712674/. 


\section{BIOGRAPHICAL SKETCH OF AUTHORS}

Kenneth M. York is a professor of management in the School of Business Administration at Oakland University. He earned his Ph.D. in Industrial/ Organizational Psychology at Bowling Green State University, and his research interests are in applied problems in human resources management.

Cynthia E. Miree is a professor of management in the School of Business Administration at Oakland University. She earned her Ph.D. in Strategic Management at the University of Pittsburgh, and her research interests are focused in the area of strategic management. 